\title{
The Effect of Tin (IV)-Protoporphyrin-IX on Bilirubin Production and Excretion in the Rat
}

\author{
P. F. WHITINGTON, A. D. MOSCIONI, AND L. M. GARTNER \\ The University of Chicago Pritzker School of Medicine and the Wyler Children's Hospital, \\ Chicago, Illinois 60637
}

\begin{abstract}
Tin (IV)-protoporphyrin-IX $\alpha$ (tin-heme) may have use in treating neonatal jaundice. To evaluate its effect on bilirubin metabolism, we measured bile-bilirubin excretion in adult, male Sprague-Dawley rats (350-500 g). After a 4-h baseline period, tin-heme $(100 \mathrm{umol} / \mathrm{kg})$ or buffer was injected subcutaneously, and bile was collected for $19 \mathrm{~h}$. Bile flow, bile salt excretion, and bile-bilirubin excretion (averaging $600 \pm 60 \mathrm{ng} / 100 \mathrm{~g} / \mathrm{min}$ for all animals) remained stable in the control period. Tin-heme treatment did not alter bile flow or bile salt excretion, but within $2 \mathrm{~h}$ bilirubin output was significantly reduced. The nadir of output was $5 \mathrm{~h}$ after injection when it was $380 \pm 40 \mathrm{ng} /$ $100 \mathrm{~g} / \mathrm{min}(p<0.001)$. Cumulative excretion over $19 \mathrm{~h}$ was reduced $30.8 \%(p<0.01)$. To determine if tin-heme interfered with hepatic uptake or excretion of bilirubin, additional animals were administered intravenous bilirubin at $30 \mathrm{mg} / \mathrm{kg} / \mathrm{h}$ for $3 \mathrm{~h}$ after tin-heme injection. Neither peak bile-bilirubin $(37.4 \pm 4.68$, control; $38.19 \pm 3.81 \mu \mathrm{g} /$ $100 \mathrm{~g} / \mathrm{min}$, treated) nor cumulative excretion $(87.8 \pm 4.7$, control; $88.9 \pm 4.2 \%$, treated) were altered. Biliary excretion of tin-heme was measured under various experimental conditions. When administered alone, maximal excretion was $4 \mathrm{~h}$ after injection $(4.41 \pm 1.58 \mu \mathrm{g} / 100 \mathrm{~g} / \mathrm{min}) ;$ by 15 $\mathrm{h}$, it fell to $0.024 \pm 0.011 \mu \mathrm{g} / \mathbf{1 0 0} \mathrm{g} / \mathrm{min} ; 20$-h cumulative tin-heme excretion in bile was $21.8 \pm 3.1 \%$ of the administered dose. Intravenous coadministration of albumin or albumin and bilirubin reduced the peak output but did not alter cumulative excretion of tin-heme. These data indicate that tin-heme reduces endogenous bilirubin formation but does not impair hepatic uptake and excretion. Bile is a major excretory route for tin-heme. (Pediatr Res 21: 487491, 1987)
\end{abstract}

\section{Abbreviations}

Tin-heme, tin (IV)-protoporphyrin-IX $\alpha$

CO, carbon monoxide

BSA, bovine serum albumin

bw, body weight

Neonatal jaundice is a disorder that affects $15 \%$ of all infants (1). Contributing to this process are overproduction of bilirubin, a vigorous enterohepatic recirculation for bilirubin, and reduced conjugation by the liver. All of these factors may be more pronounced in the premature infant where hyperbilirubinemia

Received September 29, 1986; accepted December 16, 1986.

Correspondence and reprints Peter F. Whitington, M.D., University of Chicago, Wyler Children's Hospital, Box 107, 5825 S. Maryland Avenue, Chicago, IL 60637.

Supported in part by Grants 5 RO1 HD-15050 and 2 SO7 RR-05367 from the National Institutes of Health and the Kalis Fund for Research in Pediatric Liver Disease. is a particularly vexing problem (1-7). Were it possible to delay the entry of new bilirubin into the system by inhibiting the degradation of heme, the overtaxed system of bilirubin elimination would be relieved until more mature. Of course, this should be achieved without significant toxicity.

Tin-heme is a synthetic heme analogue that is being studied as a potential therapeutic agent for neonatal hyperbilirubinemia (8). It is an effective inhibitor of heme-oxygenase in vitro, which is the initial enzyme in the sequence of heme degradation and bilirubin formation (9-11). It has been shown to lower serum bilirubin in newborn rats (12) and rhesus monkeys (13), both of which exhibit a degree of physiologic hyperbilirubinemia. It also lowers the serum bilirubin of adult patients with Gilbert's syndrome (14) and fasting Bolivian squirrel monkeys (15). It is assumed to do this through the inhibition of heme-oxygenase. This mechanism has been called into question, however, because it does not reduce the rate of excretion of $\mathrm{CO}$ in newborn rats (16), although it does in adult mice (17).

In these studies, we examined the effect of tin-heme on bilebilirubin excretion in the adult rat as a direct measure of its effect on bilirubin formation. After establishing that tin-heme significantly reduced bile-bilirubin output, we examined its effect on excretion of exogenously administered bilirubin into bile to assure the absence of an effect on hepatic uptake and excretion of bilirubin. These studies suggest tin-heme may have a potential for reducing bilirubin production without impairing bile formation and bilirubin excretion.

\section{MATERIALS AND METHODS}

Animal preparation and procedures. Adult male Sprague-Dawley rats (Holtzman Co., Madison, WI) from 250-500 g were used for these studies. With the animals under ether anesthesia, the common bile-duct was cannulated with silicone tubing $(0.20$ in id, 0.37 in od, Silastic, Dow Corning Corp., Midland, MI). A polyethylene cannula (PE-50, Clay Adams Div. of Becton, Dickinson and Co., Parsippany, NJ) was passed through the distal gastric fundus and advanced approximately $2 \mathrm{~cm}$ into the proximal duodenum where it was secured with a purse-stitch. These tubes were exteriorized through lateral abdominal stab wounds. A silicone catheter ( 0.20 in id, 0.37 in od) was inserted into the inferior vena cava via the femoral vein. A PE-50 catheter was inserted subcutaneously into the dorsal nape of the neck to facilitate the administration of test substances. Following the surgery, the animals were placed into restraining cages and maintained in a darkened and temperature-controlled $\left(37^{\circ} \mathrm{C}\right)$ box until termination of the experiments. After preliminary experiments demonstrated that a stable, low output of bilirubin was achieved within $6 \mathrm{~h}$ of surgery, they were permitted at least $12 \mathrm{~h}$ to recover prior to experimentation. During the recovery period and throughout the experiment, a fortified saline solution (57 $\mathrm{mM} \mathrm{NaCl}, 10 \%$ sucrose, $10 \mathrm{mM} \mathrm{Na}$ taurocholate) was infused through the duodenal catheter to compensate bile salt 
loss, maintain fluid balance, and provide some calories. This infusion provided $30 \mu \mathrm{mol} \mathrm{Na}$ taurocholate $/ \mathrm{kg} / \mathrm{h}$, which was empirically determined adequate to maintain stable bile flow and bile salt output. Patency of the intravenous line was maintained by an infusion of lactated Ringer's solution at $0.84 \mathrm{ml} / \mathrm{h}$. A total fluid intake of $160 \mathrm{ml} / \mathrm{kg} / 24 \mathrm{~h}$ was given to maintain hydration and bile output.

Experiments were initiated between 06:00 and 09:00 h. Bile samples were collected at hourly intervals in preweighed polyethylene tubes at $0^{\circ} \mathrm{C}$ in a refrigerated fraction collector. Animals having a stable rate of bile flow of approximately $1 \mathrm{ml} / \mathrm{h}$ were used for experimentation. At the end of the experiment, bile collection tubes were reweighed, capped, and stored at $-70^{\circ} \mathrm{C}$ until assay. Collections and analysis of bile were performed under subdued light conditions.

Experimental design. Schedule I: To Determine the Effect of Tin-Heme on Endogenous Bilirubin Output. Bile was collected for $10 \mathrm{~h}$ to establish the baseline output of bilirubin. This period was followed by a subcutaneous injection of the buffered tinheme preparation $(100 \mu \mathrm{mol} / \mathrm{kg}$ in $3.0 \mathrm{ml})$. Control animals received $3.0 \mathrm{ml}$ of the buffer. The bile collection continued for an additional $19 \mathrm{~h}$ after which the rats were sacrificed.

Schedule II: To Determine the Effect of Tin-Heme on Hepatic Excretion of Exogenously Administered Bilirubin. Bile was collected for $4 \mathrm{~h}$ to establish the baseline output of bilirubin. Thereafter, an intravenous infusion of bilirubin was given at 30 $\mathrm{mg} / \mathrm{kg} / \mathrm{h}$ for $3 \mathrm{~h}$. Simultaneous with the initiation of the bilirubin infusion, the test animals were injected subcutaneously with buffered tin-heme $(100 \mu \mathrm{mol} / \mathrm{kg}$ in $3.0 \mathrm{ml})$. One set of control animals received $3.0 \mathrm{ml}$ of buffer and the bilirubin infusion. Another set of control animals received a $3-\mathrm{h}$ infusion of BSA equal to that in the bilirubin infusion and tin-heme, $100 \mu \mathrm{mol} /$ $\mathrm{kg}$ subcutaneously.

Chemical preparations. Tin-heme (Porphyrin Products, Inc., Logan, UT) was prepared by dissolving the salt in $0.5 \mathrm{ml}$ of 0.5 $\mathrm{N} \mathrm{NaOH}$. Then $2.0 \mathrm{ml}$ of $0.1 \mathrm{M}$ Na phosphate buffer, $\mathrm{pH} 8.6$, were added and mixed. Finally, $0.5 \mathrm{ml}$ of $0.5 \mathrm{~N} \mathrm{HCl}$ was added, and if necessary, the $\mathrm{pH}$ was adjusted to 8.6. Preparations were made under subdued light conditions and used immediately.

The bilirubin infusion was prepared by a modification of the method described by Burgess et al. (18). Bilirubin (Sigma Chemical Co., St. Louis, MO) was dissolved in a small volume of 0.1 $\mathrm{N} \mathrm{NaOH}$ then brought up to volume with a buffered BSA solution. The final concentration of the infusion solution was $500 \mathrm{mg} / 100 \mathrm{ml}$ bilirubin, $17 \mathrm{~g} / 100 \mathrm{ml} \mathrm{BSA}$, and $0.02 \mathrm{M} \mathrm{Na}$ phosphate buffer, $\mathrm{pH}$ 7.5. The molar ratio of bilirubin to albumin was 3 to 1 .
Methods of analysis. Total bilirubin was measured in $25 \mu \mathrm{l}$ of bile by reaction with diazotized $p$-iodoanaline according to the procedure of Heirwegh et al. (19). The absorption readings (OD546) were converted to $\mathrm{mg} / 100 \mathrm{ml}$ by comparison to a standard curve prepared from Pediatric Versatol (General Diagnostics, Jessup, MD). We have shown that tin-heme in bile does not interfere with the measurement of bilirubin by this method (20).

Tin-heme concentrations in bile and urine were measured using the conditions of the $p$-iodoaniline assay for bilirubin, but omitting the diazotization step. In the absence of other interfering heme compounds, the OD-546 values are directly proportional to the tin-heme concentrations. Confirmation that the spectrophotometric measurements were of tin-heme was provided by thin-layer chromatographic analysis (21) of selected samples which demonstrated that tin-heme was the sole heme compound excreted from animals in these experiments.

Bile salt concentration was determined by the $3 \alpha$-hydroxy steroid dehydrognease method with fluorometric detection of the conversion of NAD to NADH as described by Fausa (22).

Statistical analysis. Differences between means of paired and group data were tested for significance using Student's $t$ test. All data are expressed as mean $\pm \mathrm{SD}$.

\section{RESULTS}

Effect of tin-heme on excretion of endogenous bilirubin. Nine animals were studied; five received tin-heme and four were controls. Bile flow was stable throughout the experiment but averaged from $0.8-1.5 \mathrm{ml} / \mathrm{h}$ for individual animals. Tin-heme administration did not alter bile flow in treated animals. The rate of bile salt excretion also did not differ between groups nor with tin-heme administration, averaging from 8.3 to $11.8 \mu \mathrm{mol} /$ h.

Figure 1 demonstrates the effect of tin-heme administration on bile-bilirubin excretion. Prior to tin-heme administration, bilirubin excretion was the same for experimental $(600 \pm 80$ to $700 \pm 60 \mathrm{ng} / 100 \mathrm{~g} \mathrm{bw} / \mathrm{min})$ and control animals $(520 \pm 170$ to $600 \pm 110 \mathrm{ng} / 100 \mathrm{~g} / \mathrm{min}$ ). After tin-heme administration, bilirubin excretion fell in treated animals. Significant reduction was achieved by $2 \mathrm{~h}(p<0.05)$, and the nadir of excretion was reached at $5 \mathrm{~h}(380 \pm 40 \mathrm{ng} / 100 \mathrm{~g} / \mathrm{min} ; p<0.001$ compared to pretreatment). From this point, excretion remained low and did not change until the experiment was terminated $19 \mathrm{~h}$ after tinheme administration. The average rate of excretion for h 3-19 after treatment was 380 to $490 \mathrm{ng} / 100 \mathrm{~g} / \mathrm{min}$ for animals receiving tin-heme versus 600 to $800 \mathrm{ng} / 100 \mathrm{~g} / \mathrm{min}$ for control animals ( $p<0.05-0.01$ for every $\mathrm{h})$.

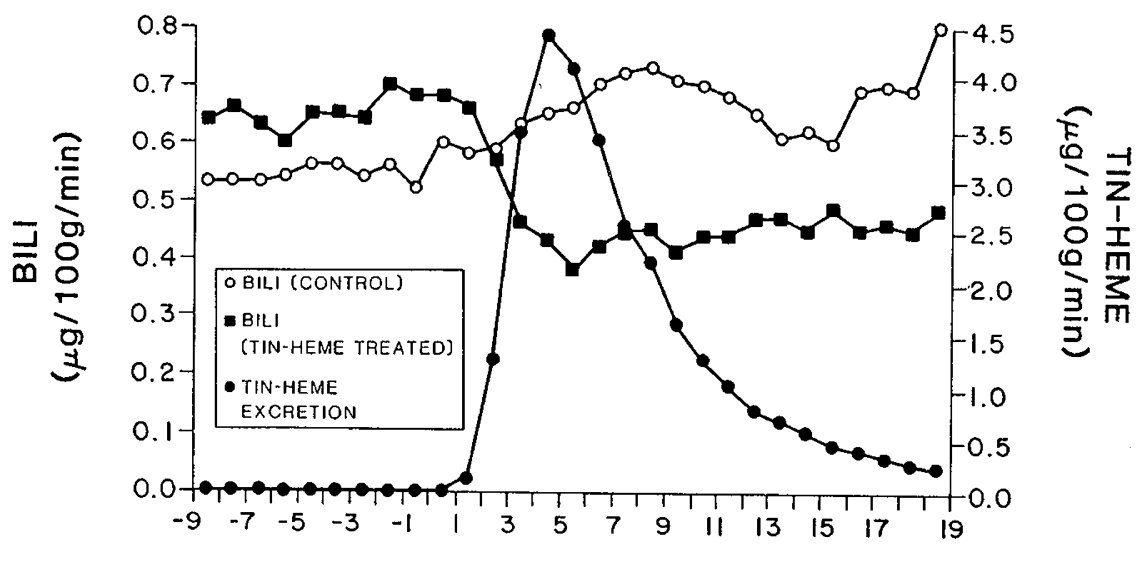

\section{HOURS}

Fig. 1. Effect of tin-heme on the rate of endogenous bilirubin excretion. The mean hourly rates of bilirubin excretion for treated and control animals are shown. Prior to tin-heme administration (at hour zero), the output did not differ and was $600 \pm 60 \mathrm{ng} / 100 \mathrm{~g} / \mathrm{min}$ for all animals. Animals after tin-heme treatment had a $30 \%$ reduced output compared to controls $(p<0.05$ for h $3-19)$. Error bars are omitted in this and other
figures for the sake of clarity. 
Figure 2 demonstrates the cumulative bile-bilirubin excretion in treated animals. There is a significant change in the slope of the line after the tin-heme injection; prior to treatment the animals excreted an average of $18.64 \mu \mathrm{g}$ bilirubin per $\mathrm{h}$, and after tin-heme, the rate was $12.90 \mu \mathrm{g}$ per $\mathrm{h}(p<0.01)$, a $30.8 \%$ reduction. The cumulative bilirubin excretion in the treated animals was $441.6 \pm 30.6 \mu \mathrm{g} / 29 \mathrm{~h}$ as compared to an expected excretion of $539.8 \pm 37.9 \mu \mathrm{g} / 29 \mathrm{~h}(p<0.002)$.

Effect of tin-heme on biliary excretion of exogenously administered bilirubin. Eleven animals received an intravenous infusion of bilirubin $(30 \mathrm{mg} / \mathrm{kg} / \mathrm{h})$ for $3 \mathrm{~h}$ (Fig. 3). Six of these animals were treated with tin-heme $(100 \mu \mathrm{mol} / \mathrm{kg})$ at the beginning of the bilirubin infusion. Five animals received buffer injections. All animals had stable baseline bile flow and bilirubin excretion which did not differ between groups. After the bilirubin infusion began, bile-bilirubin excretion increased, reaching a peak of $37.4 \pm 4.68 \mu \mathrm{g} / 100 \mathrm{~g} / \mathrm{min}$ at $3 \mathrm{~h}$ in control animals and $38.19 \pm 3.81$ at $2 \mathrm{~h}$ in tin-heme-treated animals $(p>0.1)$.

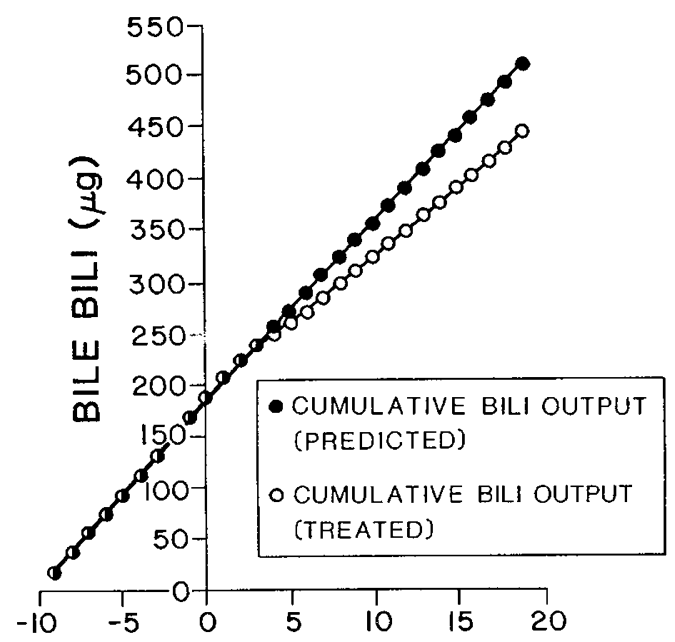

\section{HOURS}

Fig. 2. Effect of tin-heme on cumulative bilirubin output. Before tinheme therapy, bilirubin output averaged $18.64 \mu \mathrm{g} / \mathrm{h}$, whereas after, it averaged $12.90 \mu \mathrm{g} / \mathrm{h}$. The slopes of the regression lines for cumulative output were reduced an average of $30.8 \%$ by the administration of tinheme $(p<0.01)$.
Bilirubin excretion returned to baseline after $11 \mathrm{~h}$ in both groups but excretion rates thereafter were lower for the tin-heme-treated animals (400-480 ng/100 g/min for $\mathrm{h} 14-24$ after tin-heme) than for control animals $(580-690 \mathrm{ng} / 100 \mathrm{~g} / \mathrm{min})$. The cumulative excretion of bilirubin $26 \mathrm{~h}$ after initiating the bilirubin infusion was $26.52 \mathrm{mg}$ in tin-heme-treated animals and 28.46 $\mathrm{mg}$ in control animals. Adjusting for endogenous excretion and assuming a $30 \%$ reduction in animals receiving tin-heme, which was true of the control animals receiving tin-heme and albumin infusion only, the cumulative excretion was $87.8 \pm 4.7 \%$ of the administered dose in the treated and $88.9 \pm 4.2 \%$ in the control animals $(p>0.1)$.

Tin-heme excretion in bile. Figure 4 illustrates the pattern of tin-heme excretion into bile under three conditions: animals that received tin-heme but were otherwise untreated (schedule I experiments, $n=5$ ), animals which received tin-heme and intravenous bilirubin $(50 \mu \mathrm{g} / 100 \mathrm{~g} \mathrm{bw} / \mathrm{min})$ in buffered BSA solution for $3 \mathrm{~h}$ (schedule II, $n=6$ ), and animals that received tin-heme and buffered BSA solution for $3 \mathrm{~h}$ (schedule II controls, $n=5$ ). The pattern of bile excretion differed with the experimental conditions. The peak excretory rate was greatest in the animals which received tin-heme alone $(4.41 \pm 1.58 \mu \mathrm{g} / 100 \mathrm{~g} \mathrm{bw} / \mathrm{min})$. Those receiving albumin infusion had a peak excretion of 3.31 $\pm 0.85 \mu \mathrm{g} / 100 \mathrm{~g} / \mathrm{min}$ ( $p>0.1$ versus tin-heme alone). Those receiving bilirubin-albumin infusion had the lowest peak excretion, $2.18 \pm 0.81 \mu \mathrm{g} / 100 \mathrm{~g} \mathrm{bw} / \mathrm{min}$ ( $p<0.05$ versus tin-heme alone; $p<0.1$ versus tin-heme-albumin). In all animals, selected bile samples were analyzed by thin-layer chromatography, and tin-heme was the only heme compound identified.

Although the pattern of excretion was different, the cumulative excretion of tin-heme into bile did not vary among the groups. The animals receiving tin-heme alone excreted into bile $21.8 \pm$ $3.1 \%$ of the total dose in $19 \mathrm{~h}$ (the total time of collection). The urinary excretion was $22.8 \pm 5.0 \%$, so the total excretion by urine and bile was $44.6 \pm 7.0 \%$ of the administered dose. The tin-heme-albumin-treated animals excreted into bile $22.2 \pm 2.2 \%$ of the total dose in $19 \mathrm{~h}$ ( $p>0.1$ versus other groups). Urinary excretion was $23.1 \pm 2.6 \%$ in $26 \mathrm{~h}$ (the total time of collection), and the total excretion in $26 \mathrm{~h}$ was $46.7 \pm 4.3 \%$ of the administered dose. The animals that received tin-heme-bilirubin-albumin excreted into bile $17.1 \pm 2.20 \%$ of the total dose in $19 \mathrm{~h}$ ( $p$ $>0.1$ versus other groups). The urinary excretion was $25.8 \pm$ $5.0 \%$, and the total excretion in $26 \mathrm{~h}$ was $44.1 \pm 3.9 \%$ of the administered dose. Although the total excretion data are not strictly comparable because of the different total times of collec-

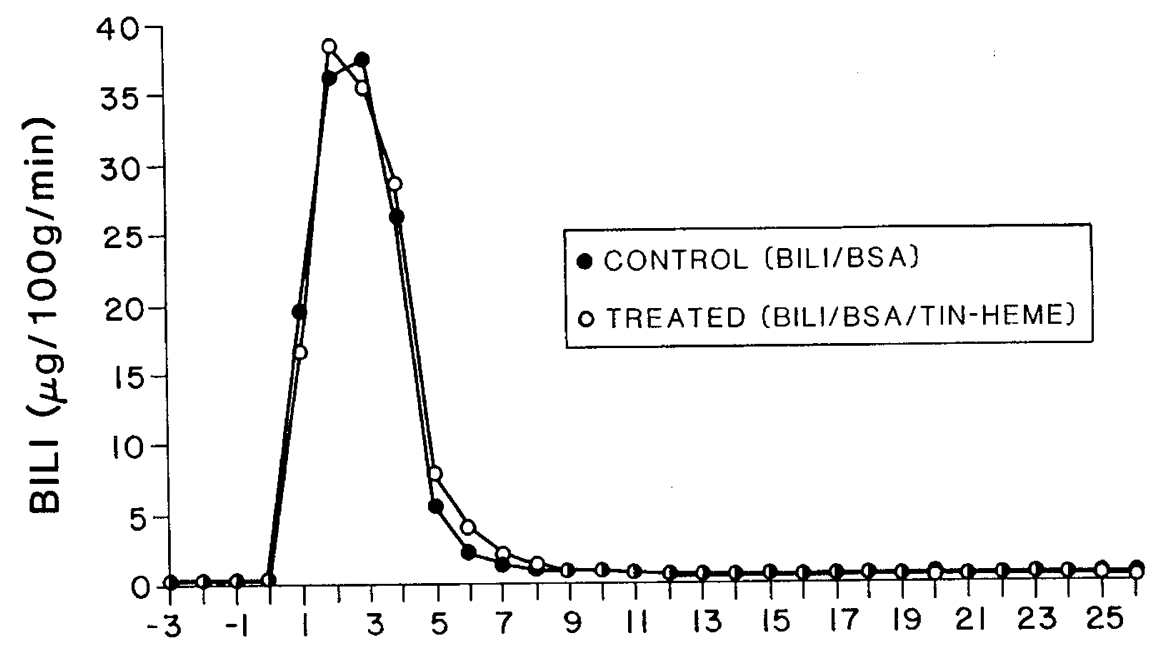

HOURS

Fig. 3. Effect of tin-heme on hepatic excretion of exogenously administered bilirubin. Tin-heme did not alter the excretion of bilirubin administered intravenously. The peak excretory rate (control: $37.4 \pm 4.7$; treated: $38.2 \pm 3.8 \mu \mathrm{g} / 100 \mathrm{~g} / \mathrm{min}$ ) or the area under the curve (cumulative excretion: control: $26.2 \pm 3.9$; treated: $26.0 \pm 4.0 \mathrm{mg} / 7 \mathrm{~h}$ ) were different between groups. 


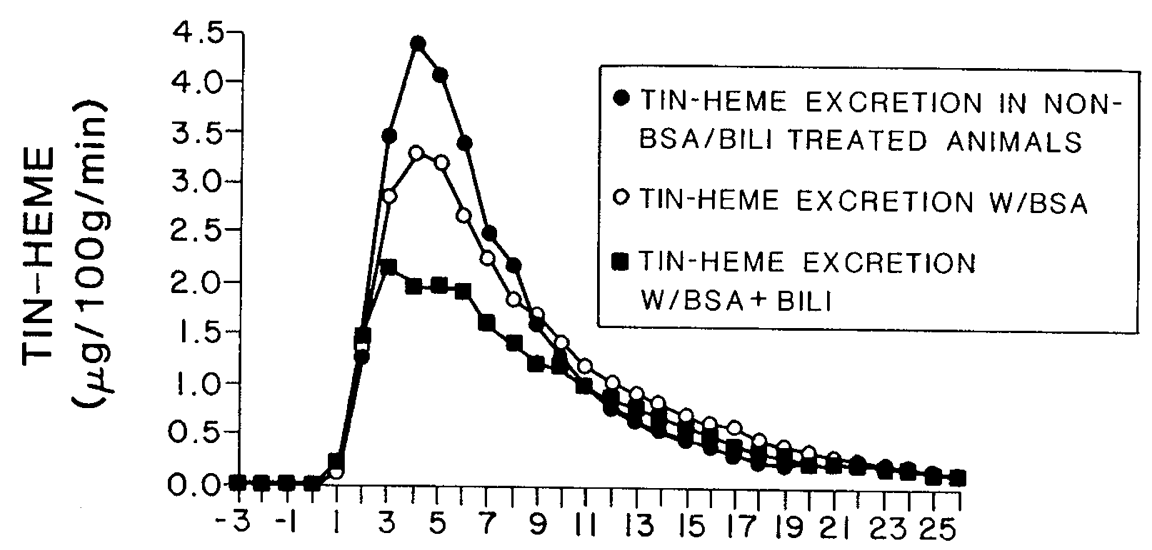

\section{HOURS}

Fig. 4. Bile tin-heme excretion in various experimental conditions. The peak rate of tin-heme excretion was reduced by the administration of albumin intravenously ( $p=$ NS compared to controls) and further by the coadministration of albumin and bilirubin intravenously ( $p<0.05$ compared to controls).

tion, they demonstrate little effect of albumin or bilirubin-albumin administration on the cumulative excretion of tin-heme.

\section{DISCUSSION}

There are several possible mechanisms by which tin-heme could reduce serum bilirubin. First, there could be reduced production of bilirubin from heme precursors through the mechanism of inhibition of heme oxygenase. This is the most likely mechanism since tin-heme and other non-Fe metaloprophyrins have been shown to inhibit heme oxygenase in vitro $(10-12)$. Second, displacement of bilirubin from albumin with deposition into tissues, perhaps including brain, might reduce serum bilirubin. Third, therapy could enhance uptake and excretion of bilirubin by the liver. Fourth, treatment could decrease the enterohepatic circulation for bilirubin. Fifth, tin-heme might result in enhanced photosensitized bilirubin destruction (23). Finally, errors in measuring bilirubin in the presence of tin-heme could create an apparent effect on serum bilirubin (20). The purpose of these experiments was to elucidate the mechanism of action of tin-heme.

Our data demonstrate that tin-heme reduces bilirubin production in the adult laboratory rat. Biliary output of endogenous bilirubin was reduced by $30.8 \%$. Measuring bilirubin in the presence of tin-heme is difficult, but our other work has demonstrated the accuracy of the assay used in these experiments (20). We found in preliminary experiments that biliary bilirubin output was much higher in the first few hours after surgery, but reached a low, stable output (equal to production) by $6 \mathrm{~h}$. The early high rate of bilirubin output could have resulted from pigment within the intestinal tract or from tissue injury at the time of surgery. We measured the effect of tin-heme only after a prolonged period of stabilization after biliary diversion so that the consistent reduction following tin-heme administration was the result of reduced (steady-state) production. The amount of reduction is remarkably similar to that observed by other investigators using the measurement of CO output (17). Simionatto et al. (24) have presented similar results in studies of bile-bilirubin output in adult rats in experiments similar to these. However, in those studies, the animals were not given a long recovery period to reach steady state bilirubin output, and they were not supplemented with bile salt so bile salt output and bile flow fell with time (24). These experiments were performed in such a way that the reduced bile-bilirubin observed represents the in vivo effect of tin-heme on steady state bilirubin output.

The observed reduction in bilirubin output could have been related to inhibition of bilirubin uptake and/or excretion by the liver. This would be somewhat inconsistent with the observations of others in which serum concentration was reduced. However, to prove that bilirubin is handled normally by the liver, we examined the effect of tin-heme on the excretion of exogenously administered bilirubin into bile. We administered a dose of bilirubin which resulted in a 100 -fold increase in bilirubin output, so we assume that hepatic processes for uptake and secretion were saturated. Our data demonstrate no effect of tin-heme on the excretion of an intravenous bolus of bilirubin. Moreover, tin-heme administration did not reduce the rate of bile flow or bile salt excretion under the conditions of the steady infusion of taurocholate into the duodenum. Thus, tin-heme does not appear to have an effect on the hepatic handling of bilirubin or bile formation.

The duration of effect of tin-heme is not entirely clear. Reduced serum bilirubin can be seen for 10-14 days after administration of tin-heme (11), tissue heme oxygenase activity is reduced for 7 days (25), and reduced CO output lasts at least 18 h (17). Our experiments were not carried out long enough to completely characterize the duration of reduced bilirubin production. However, animals treated in schedule II, in which bile bilirubin output was measured for $26 \mathrm{~h}$, exhibited a return to pretreatment rates of bilirubin output by $20-22 \mathrm{~h}$ after injection. Also, two animals treated in schedule I maintained steady bile flow and could be studied for $24 \mathrm{~h}$. Both had returned to pretreatment bilirubin output by $21 \mathrm{~h}$. Thus, it seems that tinheme has a duration of in vivo activity of about $20 \mathrm{~h}$ in adult rats at the dose used in these studies.

These experiments allowed us to measure the excretion of tinheme after subcutaneous injection. Overall excretion via bile and urine was $44-47 \%$ of the administered dose in 19-26 h. Other investigators have shown $50 \%$ excretion in 7 days in adult rats (25). Although excretion was slowing dramatically by the end of our collections, it is unlikely that 6 additional days would not have resulted in more than $5 \%$ additional excretion. Anderson et al. (25) showed only $15.4 \%$ of the total dose in stool (all in the first 3 days), but we found about $20 \%$ in bile in the first $19 \mathrm{~h}$. An explanation for this observation which would also explain the difference in overall excretion would be an enterohepatic recirculation for tin-heme. We tested this hypothesis by administering tin-heme by duodenal tube and measuring bile output of tin-heme in two rats. In neither was any tin-heme detected in bile. Lack of oral absorption has also been demonstrated in adult humans (14). Thus, bile seems to be a major and final excretory route for tin-heme. We have no explanation for the evident greater excretion in these animals than most previously studied except for the difference in dosage- $100 \mu \mathrm{mol} / \mathrm{kg}$ in our studies versus $50 \mu \mathrm{mol} / \mathrm{kg}$ in the previous work (25).

The pattern of tin-heme excretion in bile suggests an interac- 
tion between tin-heme and albumin which is modified by bilirubin. Albumin given intravenously reduced the peak excretory rate, and albumin-bilirubin further reduced it. There was no effect on cumulative biliary excretion after $19 \mathrm{~h}$, so the pattern was simply blunted and skewed to the right. The half-time for disappearance of tin-heme from plasma in rats has been reported as $3.4 \mathrm{~h}(25)$, which explains the sharply falling bile output of tin-heme after the initial rise. How the potential albumin-bilirubin-tin-heme interaction could affect the pharmacology and toxicology of tin-heme when administered to jaundiced human neonates remains to be determined.

These investigations have been limited to adult rats so far. The study of Cowan et al. (16) suggests that the effect of tin-heme on endogenous bilirubin production may be different in the newborn of the species. While it is difficult to perform these detailed physiologic studies in newborn rats due to their small size, such studies are indicated to fully understand the mechanism of action of this new potential pharmacologic agent.

\section{REFERENCES}

1. Odell GB 1976 Neonatal jaundice. In Popper H, Schaffner F (eds) Progress in Liver Disease, Vol V. Grune \& Stratton, New York, pp 457-475

2. Maisels MJ, Pathak A, Nelson NM, Nathan DG, Smith CA 1971 Endogenous production of carbon monoxide in normal and erythroblastotic newborn infants. J Clin Invest 50:1-8

3. Pearson HA 1967 Life-span of the fetal red blood cell. J Pediatr 70:166-171

4. Bartoletti A, Stevenson DK, Ostrander CR, Johnson JD 1979 Pulmonary excretion of carbon monoxide in the human as an index of bilirubin production. I. Effects of gestational and postnatal age and some common neonatal abnormalities. J Pediatr 94:952-955

5. Poland RL, Odell GB 1971 Physiologic jaundice: the enterohepatic circulation of bilirubin. N Engl J Med 284:1-6

6. Gartner LM, Lee K, Vaisman S, Lane D, Zarafu I 1977 Development of bilirubin transport and metabolism in the newborn rhesus monkey. J Pediatr 90:513-531

7. Kawade N, Onishi S 1981 The prenatal and postnatal development of UDPlucoronyltransferase activity towards bilirubin and the effect of premature birth on this activity in the human liver. Biochem J 196:257-260

8. Kappas A, Drummond GS 1985 Synthetic metalloporphyrins: a class of compounds of pharmacological interest. Bioeassays 3:256-259
9. Drummond GS, Kappas A 1981 Prevention of neonatal hyperbilirubinemia by tin protoporphyrin IX, a potent competitive inhibitor of heme oxidation. Proc Natl Acad Sci USA 78:6466-6470

10. Maines MD 1981 Zinc-protoporphyrin is a selective inhibitor of heme oxygenase activity in the neonatal rat. Biochim Biophys Acta 673:339-350

11. Kappas A, Drummond GS, Simionatto CS, Anderson KE 1984 Control of heme oxygenase and plasma levels of bilirubin by a synthetic heme analogue, tin-protoporphyrin. Hepatology 4:336-341

12. Drummond GS, Kappas A 1982 Chemoprevention of neonatal jaundice: potency of tin-protoporphyrin in an animal model. Science 217:1250-1252

13. Cornelius CE Rodgers PA 1984 Prevention of neonatal hyperbilirubinemia in Rhesus monkeys by tin-protoporphyrin. Pediatr Res 18:728-730

14. Anderson KE, Simionatto CS, Drummond GS, Kappas A 1986 Disposition of tin-protoporphyrin and suppression of hyperbilirubinemia in humans. Clin Pharmacol Ther 39:510-520

15. Chowdhury JR, Portman OW, Chowdhury NR, Alexander M, Cornelius CE, Arias IM 1982 Mechanism of fasting hyperbilirubinemia: studies in Bolivian squirrel monkeys. Hepatology 2:723(abstr)

16. Cowan BE, Kwong LK, Vreman HJ, Stevenson DK 1983 The effect of tin protoporphyrin on the bilirubin production rate in newborn rats. Pediatr Pharmacol 3:95-100

17. Milleville GS, Levitt MD, Engel RR, 1985 Tin protoporphyrin inhibits carbon monoxide production in adult mice. Pediatr Res 19:94-96

18. Burgess GH, Oh W, Bratlid D, Brubakk AM, Chashore WJ, Stonestreet BS 1985 The effects of brain blood flow on brain bilirubin disposition in newborn piglets. Pediatr Res 19:691-696

19. Heirwegh KPM, Fevery J, Meuwissen JATP, DeGroote J, Compernolle F, Desmet V, Van Roy FP 1974 Recent advances in the separation and analysis of diazo-positive bile pigments. Methods Biochem Anal 22:205-250

20. Moscioni AD, Whitington PF, Gartner LM 1986 Total bilirubin measurement in the presence of tin-protoporphyrin-IX. A comparison of four standard laboratory methods. Clin Chem (in press)

21. Kappas A, Simionatto CS, Drummond GS, Sassa S, Anderson KE 1985 The liver excretes larger amounts of heme into bile when heme oxygenase is inhibited by Sn-protoporphyrin. Proc Natl Acad Sci USA 82:896-900

22. Fausa $\mathrm{O} 1975$ Quantitative determination of serum bile acids using a purified $3 \alpha$-hydroxysteroid dehydrogenase. Scand J Gastroenterol 10:747-75

23. McDonagh AF, Palma LA 1985 Tin-protoporphyrin: a potent photosensitizer of bilirubin destruction. Photochem Photobiol 42:261-264

24. Simionatto CS, Anderson KE, Drummond GS, Kappas A 1985 Studies on the mechanism of Sn-protoporphyrin suppression of hyperbilirubinemia. J Clin Invest 745:513-521

25. Anderson KE, Simionatto CS, Drummond GS, Kappas A 1984 Tissue distribution and disposition of tin-protoporphyrin, a potent competitive inhibitor of heme oxygenase. J Pharmacol Exp Ther 288:327-333 